\title{
ORGANIZATIONAL, MARKET AND LEGAL CONSEQUENCES OF THE 2013 REFORM IN VOLUNTARY HEALTH INSURANCE IN BULGARIA
}

\author{
Antoniya Dimova ${ }^{1}$, Maria Valkanova ${ }^{2}$ \\ ${ }^{1}$ Department of Health Economics and Management, Faculty of Public Health, \\ Medical University of Varna \\ ${ }^{2}$ Department of Social Medicine and Organization of Healthcare, Faculty of Public Health, \\ Medical University of Varna
}

\begin{abstract}
INTRODUCTION: Voluntary health insurance (VHI) in Bulgaria was reformed in the period 2012-2013 following the need to synchronize Bulgarian VHI legislation with the EU requirements. All VHI companies (VHICs) had to be relicensed under the terms of the Insurance Code and had to obtain license for sickness insurance or for sickness and accident insurance.

AIM: The aim of the study is to analyze some major consequences for the organization of VHIs and market development using scientific literature and other official sources, legislative acts, and databases, performing comparative and structural market and juridical analyses.

RESULTS: The reform introduced two important changes. First, the statute of VHICs has changed from such intended solely for VHI to companies, which can offer other insurance products as well. Second, instead of providing predefined and licensed benefit packages under the regulation of the Health Insurance Act, insurance companies, offering VHI, establish their own insurance products based on a contract for medical insurance. The number of individuals holding VHI increased from less than $3 \%$ of the population in 2010-2013 to $9.8 \%$ in 2016. VHI expenditure grew by $28.8 \%$ in value in 2015 compared with 2013 .

CONCLUSION: The increased number of the insured individuals is most probably be due to achieved synergetic effect by the general and life insurance companies. It could be expected that their number will continue to rise. The diversity of VHI services is strongly related to the legislative change due to the new legal requirements and the introduction of the contracts for medical insurance.
\end{abstract}

Keywords: voluntary health insurance, reform, Bulgaria

\footnotetext{
Address for correspondence:

Accos. prof. Antoniya Dimova, PhD

Department of Health Economics and Management

Faculty of Public Health

Medical University of Varna

55 Marin Drinov St

9002 Varna

Bulgaria

e-mail:ant_dimova@abv.bg
}

Received: June 20, 2018

Accepted: July 11, 2018 


\section{INTRODUCTION}

Voluntary health insurance (VHI) was introduced with the 1998 Health Insurance Act, along with the establishment of the social health insurance system in Bulgaria. The main aim was to diversify revenue sources for the health system and thus, possibly, to assure ground for financial stability of the system. However, the VHI market stayed limited, covering only a small share of the population with an insignificant impact on the health system financing. The development of the VHI market has caused a great deal of debate among the politi$\mathrm{cal}$ and professional groups. Strengthening the VHI role in health system financing was an aim acknowledged by the policy-makers since its introduction in 1998 but there was no clear vision of the appropriate changes in both social (compulsory) and voluntary health insurance.

In 2012, by meaningful changes in the Health Insurance Act, VHI in Bulgaria was reformed following the need to synchronize Bulgarian VHI legislation with the EU's general insurance legislation (14). There was a one-year period, 2012-2013, of implementing the reform.

Until 2013, VHI was provided by for-profit joint-stock companies intended for voluntary health insurance only, called VHI companies (VHICs). These VHICs could operate after receiving a licence from the Financial Supervision Commission (FSC). The first VHICs were licensed in 2001 and their number gradually increased to 20 in 2010 (5). In 2012 , nineteen VHICs operated on the health insurance market. The biggest company had a $12.8 \%$ market share and the six largest companies accounted for a total of $61.1 \%$ of the VHI market (6). VHICs provided seven benefit packages: (1) Prevention; (2) Outpatient care; (3) Hospital care; (4) Dental care; (5) Other services related to care provision (such as a private hospital room, nursing and rehabilitation services provided during hospitalization or at home, medical transportation); (6) Reimbursement of costs, and (7) other plans (complex medical care) $(1,2)$. Each benefit package had to be licensed by the FSC. A benefit package could be established or changed with the approval of FSC. Each package was offered with two options, which included (1) minimum/basic; and (2) extended/luxury or full option. The options differed from one another in the number of services which were covered by the VHIC. The choice of a certain package and option was negotiated between the insured individuals and the insurance company. Usually contracts were signed on an annual basis but there was also possibility of a shorter (one month) or longer (three years) period. Individuals with VHI could choose between a reimbursement and a benefits-in-kind model. If they chose the reimbursement model, they first paid the provider out of pocket after which the VHIC reimbursed the insured person fully or partially for health costs. The reimbursement amount had been set in advance in the insurance contract or the contract could specify that the subscriber was to receive a fixed amount related to treatment expenses. If patients chose the benefits-in-kind model, the VHIC paid contracted health care providers directly for providing predetermined health services and goods. VHICs selectively contracted with both private and public health care providers or they could establish their own health providers and pharmacies. In both cases, the level of provider remuneration was determined by the market. The most common payment mechanism was fee-for-service. For each VHI package, the insured individuals paid premiums. Premium levels as well as the time limit and the way of payment were defined according to existing company tariffs, which also had to be approved by FSC.

By August 2013, all VHICs had to be relicensed under the terms of the 2005 Insurance Code (as specified by a change to the 1998 Health Insurance Act), and operating as companies for general or mixed insurance (life insurance and general insurance for sickness and accident). From all VHICs, ten were relicensed, three merged, and six terminated their activity (7). The above-mentioned predefined benefit packages were replaced with contracts on medical insurance, covering financial risks related to loss due to illness or to the provision of health services and goods.

Although the reform in the VHI sector from 2013 was motivated solely by the necessity to synchronize the Bulgarian regulations with the EU's insurance legislation, some changes on the market are visible. 


\section{AIM}

The aim of the study is to analyze some major consequences to the organization of the VHI and market development resulted from the new legislative regime of the insurance companies and the policies they provide.

\section{MATERIALS AND METHODS}

We use as a basis our previous research on the VHI development in Bulgaria since its introduction $(1,2,8)$, considering the market role, size and structure before and after the 2013 reform as well as public policies in this field. The research is further extended with the latest data by Eurostat Database, the WHO's Global Health Expenditure Database, and the FSC's Database on the general and life insurance market in Bulgaria. We performed structural and trend analyses in regard to VHI market development. Comparative analysis of the market before and after the reform was hampered by inconsistency and incomparability of data due to the new legislative regime of the insurance contracts and the different type of data reported by the insurance companies. The research, therefore, was deepened with a legal analysis on the contracts on medical insurance, based on legislative acts and scientific juridical literature.

\section{RESULTS AND DISCUSSION}

\section{Shaping the VHI Activities}

The 2012-2013 reform in VHI introduced two important changes. First, the statute of the insurance companies providing VHI has changed from such intended solely for VHI to companies, which can offer other insurance products as well. Second, instead of providing predefined and licensed benefit packages under the regulation of the Health Insurance Act, insurance companies offering VHI establish their own insurance products, defined as "sickness insurance", under the regulation of the 2005 Insurance Code (replaced by the 2016 Insurance Code). In this regard, all VHICs had to be relicensed under the terms of the Insurance Code in 2012-2013 in order to continue to operate and had to obtain license for sickness insurance or for both sickness and accident insurance. In addition, this transformation gave opportunity to the already existing insurance companies to start offering VHI as well. This significantly changed the VHI market landscape. The regula- tion of the VHI under the Insurance Code extended its nature: from bearing risks related to the financial provision of health services and goods (in the field of propriety insurance) to covering risks of an accident or illness through payment of fixed amounts, regardless of the costs incurred, or through payment of benefits, as well as through a combination of the two types of payment (both propriety and non-propriety insurance).

Both general and life insurance companies can provide sickness and accidents insurance after obtaining the respective licenses. In accordance to the Insurance Code, an insurance company could obtain licenses under general and life insurance classification groups (an insurer with mixed activity) only in regard to sickness and accident insurance. According to the Health Insurance Act, VHI can be provided by insurers, which have license for sickness or both sickness and accident insurance under the general insurance classification.

Both the Health Insurance Act and Insurance Code regulate VHI as based on a contract on medical insurance. Under the medical insurance contract, the insurer covers risks arising from a sickness or accident related to the financial provision of certain health services and goods, against payment of an insurance premium by the insured person. The law allows the insurer to assume the financial provision of: (a) health services and goods related to the prevention of the insured person, pregnancy, childbirth, etc. and (b) other goods and services related to the healthcare of the insured, including transport, specialized care and palliative care. Provision of health services and goods can be assured based on a contract between the insurer and respective health providers.

The contact for medical insurance is a type of property insurance. This emanates from its compensatory nature. The subject of the medical insurance contract is the treatment costs of the insured, i.e. a property good, not life, health and working capacity of the insured (9). Therefore, the medical insurance is provided by insurance companies, which are licensed for general insurance (property insurance). However, it is also offered by life insurers because it is related to non-property benefits of the insured person, such as health and life (10). The medical insur- 
ance contract can cover risks associated with loss of income due to an accident or illness, and the insurer undertakes to compensate, through one-off or periodic payments, for the loss of income of the insured person. The contract may set a maximum amount of the insurer's liability in the form of a lump sum or as a volume and scope of health services and goods provided for a predefined period. In contrast to the personal accident insurance, under the medical insurance contract, the illness does not necessarily lead to temporary or permanent loss of working capacity. The personal accident insurance is not considered as VHI.

Based on contracts on medical insurance, insurers offer a wide range of different insurance packages, which cover outpatient, inpatient, dental care, home treatment, medical transportation, medicines, and medical devices. Prophylaxis is also included in some of them. Insurance companies provide different coverage for oncological, chronic, and mental diseases. Some companies may completely exclude oncological diseases, while others may cover only diagnostics and first stage treatment (11). Thus, the VHI substantially changed in terms of increased diversity of insurance products. Instead of the previously existing seven benefit packages, which had to be licensed by the FSC, insurance companies now develop their own insurance products.

\section{Structure}

Change of the VHI Market Role, Size and

VHI is intended to cover complementary services and goods, which are not covered by the social health insurance fund (which is the National Health Insurance Fund, NHIF) and supplementary services (for example, better service and free choice of a hospital physician or team). However, VHI in Bulgaria largely covers services, which are included in the NHIF benefit package as well. This means that, in practice, for some services, individuals with VHI have double coverage. It is a well-recognized fact that the broad and complicated benefit package of the NHIF is among the leading reasons for the underdeveloped VHI market. VHI expenditure amounted to only $0.3 \%$ of the total health expenditure and $0.7 \%$ of the private health expenditure in 2005 (12) and stayed approximately the same in $2015-0.4 \%$ of the total health expenditure and $0.8 \%$ of the pri- vate health expenditure (13). The number of individuals holding a VHI increased from less than 3\% of the population in the period 2010-2013 to $9.8 \%$ in 2016. When VHICs stopped their activity in 2013, the number of people with VHI coverage decreased by $16.3 \%$ to a total of 175000 insured individuals ( 2.4 $\%$ of the total population) compared to 2012 (14). Until 2016 the number of individuals holding a VHI increased to 700451 people $(9.8 \%$ of the total population). VHI expenditure grew by $28.8 \%$ in value and by $14.3 \%$ as a percentage in the current health expenditure structure in 2015 compared with 2013 (15). Traditionally, most of the VHI clients are companies who purchase polices in favor of their employees, although their relative market share is declining from $98 \%$ in 2009 to $85-90 \%$ in $2016(16,17)$. Individual policies account for $10-15 \%$, most of which cover family members of individuals insured by their employer (17). This dominance persists further, as corporate clients reached $96 \%$ of all newly signed contracts in 2016. In contrast, in 2015, the majority of the newly signed contracts (71\%) were individual. This change in policies structure could explain the 34\% increase in the number of individuals with $\mathrm{VHI}$ in 2016 compared to a year before. Most of the voluntary health-insured individuals (96\%) are between 18 and 65 years of age, and only $3 \%$ are children under 18 years. The share of insured people over 65 years of age decreased from $1.5 \%$ in 2015 to $0.9 \%$ in 2016 mainly due to the fact that most of the policies in 2016 were corporate (18). Since 2013, outpatient curative and rehabilitation care accounted for the biggest share in the total current VHI expenditure $(1,2)$. Fifty-one percent of the voluntarily health-insured individuals had coverage for outpatient medical services in $2016,42.5 \%$ - for hospital care, $38.4 \%$ for preventive care, and $17.2 \%$ for dental services (18). Most of the insured individuals have combined coverage. For comparison, in 2011-2013, around 30\% of all premiums and between 30 and $40 \%$ of the claims were in regard to combined VHI plans $(5,6)$.

\section{Preliminary Effects of the Change}

As a result of the 2013 reform, sickness and incident insurance premium income on the general insurance market increased by $126.1 \%$ in 2013 compared to 2012, and increased further with more than $100 \%$ in the first half of 2014 (19). Group sickness in- 
surance recorded the biggest growth on the general and life insurance market in 2013 and $2014(19,20)$. In 2015 and 2016, sickness insurance total premiums income and payments continued to grow. Sickness insurance premiums and payments, provided on the life insurance market, even outpaced the increase on the general insurance market.

Until 2013, the FSC maintained a comprehensive database on the VHI market, providing financial and market share data by VHICs and by benefit packages. Currently, the insurance companies report their activity to the FSC only by type of insurance such as sickness and accident insurance. In addition, some contracts on medical insurance are reported to the FSC by other classification groups such as "accident" or "travel assistance" (17). This inaccuracy in grouping $\mathrm{VHI}$ into these classification groups leads to incomplete data on the VHI market. In 2017, fourteen general and seven life insurance companies reported income by sickness insurance to the FSC $(21,22)$. Currently, data on VHI coverage by type of health services can be found in reports and analyses by the Executive Agency Medical Audit (EAMA), an agency of the Ministry of Health, which supervises the VHI market in regard to quality of health services provided under the contracts on medical insurance. Comparing data from EAMA (18) with the FSC's data on sickness insurance, it became evident that not all insurance companies, which reported premium income by sickness insurance in 2016, offered packages for VHI supervised by EAMA.

\section{CONCLUSION}

Although the period after the legislative change in VHI is relatively short and there is not enough evidence to link observed changes on the market to the reform, some general conclusions and expectation could be outlined. After the reform, the number of VHI individuals increased, most probably due to achieved synergetic effect by the general and life insurance companies. It could be expected that the number of covered individuals will continue to rise in the next few years. The diversity of the VHI services is strongly related to the legislative change due to the new legal requirements to the VHICs and the introduction of the contracts for medical insurance. Medical audit over the VHI activities as well as mar- ket analyses could be hampered by lack of comprehensive and consistent data.

\section{REFERENCES}

1. Dimova A, Rohova M., Moutafova E, Atanasova E, Koeva S, Panteli D, van Ginneken E. Bulgaria: health system review. Health Systems in Transition. 2012;14(3):1-186.

2. Dimova A. Bulgaria. In: Sagan A, Thomson S, editors. Voluntary health insurance in Europe: Country experience [Internet]. Copenhagen (Denmark): European Observatory on Health Systems and Policies; 2016. (Observatory Studies Series, No. 42.)

4. Available from: https://www.ncbi.nlm.nih.gov/ books/NBK447702/

3. Radeva M. Legal framework of the voluntary health insurance. Scientific proceeding of the Russe University. 2012; 51(7):241-5. (in Bulgarian)

4. Natalia M. Shtereva-Nikolova \& Nikolay A. Popov \& Tsvetelina M. Petrova-Gotova, 2014. „The Voluntary Health Insurance In Bulgaria - History, Development And Changes, Economy \& Business Journal, International Scientific Publications, Bulgaria, vol. 8(1), pages 341-345.

5. FSC, Statistic on voluntary health insurance market (in Bulgarian). Sofia, Financial Supervision Commission 2011 (http://www.fsc.bg/bg/podnadzorni-litsa/statistika/pazar-po-dobrovolno-zdravno-osiguryavane/, accessed 4 September 2018)

6. FSC, Statistic on voluntary health insurance market (in Bulgarian). Sofia, Financial Supervision Commission 2013 (http://www.fsc.bg/bg/podnadzorni-litsa/statistika/pazar-po-dobrovolno-zdravno-osiguryavane/, accessed 4 September 2018).

7. Neikov, FSC re-licensed the health insurance companies. Ivestitor.BG, 7.08.2013 (Available at: https:// www.investor.bg/ikonomika-i-politika/332/a/kfnprelicenzira-zdravnite-drujestva-v-zastrahovateli-155651/, accessed 12.01.2018)

8. Dimova A, Rohova M, Koeva S, Atanasova E, Koeva L, Kostadinova T, Spranger A. Bulgaria: health system review. Health Systems in Transition. 2018;xx(x):1-xxx (in press).

9. Goleva P. Insurance and reinsurance Law, Sofia, 2000, p. 420 (in Bulgarian)

10. Yordanova E Health Insurance - Nature and Benefits, „Finance and Law”, 9/2002/, p.80 (in Bulgarian) 
11. Capital, Newspaper. Double health insured. January 13, 2017 (Available at: https://www.capital.bg/ pazari/lichni_finansi/2017/01/13/2898489_dvoino_ zdravno_podsiguren/, accessed 12.01.2018)

12. WHO National Health Accounts, 2011 quoted in: Dimova A, et al. Bulgaria: health system review. Health Systems in Transition. 2012;14(3):1-186.

13. WHO Global Health Expenditure Database, 2018

14. FSC (1/2013), An overview of non-bank financial sector in Bulgaria (in Bulgarian). Sofia, Financial Supervision Commission (Available at: http://www. fsc.bg/bg/za-komisiyata/analizi-na-kfn/, accessed 13.01.2018).

15. Eurostat, 2017 Eurostat [online database]. Brussels, European Commission (accessed 6 Sept 2017)

16. CPC. Analysis of the voluntary health insurance competitive environment (in Bulgarian). Sofia, Commission on Protection of Competition (http:// reg.cpc.bg/DepartmentDecisions.aspx?vp=4, accessed 2 May 2018)

17. Capital. Newspaper. Health insurance increases, January 2, 2017 (Available at: https://www.capital. bg/specialni_izdaniia/zdrave/2017/01/02/2884790_ zdravnite_zastrahovki_narastvat/, accessed 12.01.2018)

18. EAMA. Annual Report on Condition and Overall Activity of the Health Insurance in Republic of Bulgaria for 2016. MoH, Sofia, 2017 (Available at: http://eama.bg/images/Dokladi/Zdravno\%20osigurjavane\%202016.pdf, accessed:10.02.2018)

19. FSC. An overview of non-bank financial sector in Bulgaria (in Bulgarian). Sofia, Financial Supervision Commission, 3/2013

20. FSC (2/2014). An overview of non-bank financial sector in Bulgaria (in Bulgarian). Sofia, Financial Supervision Commission (Available at: http:// www.fsc.bg/bg/za-komisiyata/analizi-na-kfn/, accessed 13.01.2018)

21. FSC, 2018 Statistics on market of general insurance (Available at: http://www.fsc.bg/bg/pazari/ zastrahovatelen-pazar/statistika/obshto-zastrahovane/, accesses 12.04.2018)

22. FSC, 2018 Statistics on life insurance market (Available at: http://www.fsc.bg/bg/pazari/zastrahovatelen-pazar/statistika/zhivotozastrahovane/, accesses 12.04.2018) 